\title{
Detecting modern desert to urban transitions from space in the surroundings of the Giza World Heritage site and Greater Cairo
}

\author{
J.Manuel Delgado ${ }^{\mathrm{a}, \mathrm{b}}$, Gert Verstraeten ${ }^{\mathrm{b}}$, Ramon F. Hanssen ${ }^{\mathrm{a}}$ \\ ${ }^{a}$ Department of Geoscience and Remote Sensing, Delft University of Technology, Stevinweg \\ 1, 2628CN, Delft, P.O. Box 5048, 2600 GA Delft, (The Netherlands) \\ ${ }^{b}$ KU Leuven Division of Geography, Celestijnenlaan 200E BOX 2409, 3001 Leuven
}

(Belgium)

\begin{abstract}
During the last decades, Greater Cairo, Egypt, is increasing in population and in built-up extension. Some of the new buildings are informal, constructed in absence of government planning processes, and threaten the Heritage Cultural Site of the Giza Pyramids. In addition, the fertile land of the Nile floodplain is being urbanized despite the government's building prohibition since the 1990s. Therefore, constant monitoring of construction activity is crucial in the rapidly changing environment of this area. Here we present a data fusion approach that overcomes the limitations of single medium resolution sensor approaches, and also identifies areas in transition from desert to urban. We use multi-temporal multi-sensor supervised land use classification and include a new land use class for detecting undefined disturbances. Synthetic Aperture Radar (SAR) data is combined with multi-spectral data for creating the land use land cover (LULC) maps using artificial neural networks (ANN). Specifically, ERS SAR data is combined with Landsat 5TM for 1998 and Envisat ASAR IMS with Landsat 7 ETM+ for 2004 and 2010. With this
\end{abstract}


data fusion approach, it is measured an increase of $73 \%$ of Greater Cairo built-up extent from 1998 to 2010. Finally, we show the relationship between the aforementioned disturbances and the new built-up areas, detecting $26 \%$ of the total new built-up areas constructed from 1998 to 2010 where undefined disturbances were identified in previous land use maps.

Keywords: data fusion, land use classification, urban expansion, SAR, Landsat, Greater Cairo, Giza

\section{Introduction}

The world is becoming progressively urbanized. Especially in developing countries, this trend has been accelerating over the last two decades. Over the next 30 years, the world's population growth is expected to be concentrated in urban areas within the developing world (Vermeiren et al., 2012). The challenges for achieving sustainable urban development will be particularly significant in Africa (Cohen, 2006). This is certainly true for Cairo, the most populous urban agglomeration in Africa. The urban sprawl of Cairo during the last decades resulted in the replacements of the fertile floodplain of the River Nile by urban structures. From the time of the 1996 population census onwards, the Egyptian government has tried to avoid new constructions in the Nile floodplain by encouraging people to live outside the so-called 'green land' and settle in the arid areas of the eastern and western desert plateau (Sutton \& Fahmi, 2001). Despite the restrictions introduced in 1996 inner-city slums grew, and informal settlements bloomed on the urban fringe (Harris \& Wahba, 2002). What is particularly troublesome is the increasing urban pressure on the Giza pyramids plateau, designated as UNESCO World Heritage Site 
(WHS) and protected by the 1972 World Heritage Convention (UNESCO, 2008). Debate between scholars, practitioners and activists over development activities within and around this unique site is leading to growing conflict between conserving the archaeological site on the entire plateau and developing the surrounding areas (Shetawy \& El Khateeb, 2009).

Detailed mapping and monitoring of the evolution of Cairo's urban structure and morphology is therefore needed for an effective management policy and a comprehensive view on urban governance and protection of cultural heritage. Several studies have discussed remote sensing techniques to monitor and analyse dynamic expansion and urbanization in Greater Cairo. Most of them have made use of optical sensors (de Noronha Vaz et al., 2011b; Hassan, 2011).

However, using just optical data, distinguish between different objects composed of the same material can be difficult. Stewart et al. (2004) reported difficulties in spectrally distinguishing urban and desert features from optical sensors in the desert areas of Greater Cairo, due to the heavy layer of sand/dust that coats buildings and the fact that in this area construction materials are sourced from the nearby desert land.

Analysis using only Synthetic Aperture RADAR data and their derived coherence products might also produce misclassification of areas with high temporal variability (Delgado et al., 2013). Therefore, our assumption is that in this case, contrary to the natural behaviour of the coherence maps, low coherence does not represent only water or fields (Bruzzone et al., 2004) but 
also areas where other activities are ongoing (Milisavljevic et al., 2010). Hence, we define a new land use class for detecting these areas and differentiating them among other classes.

This paper proposes the analysis of the optical and SAR data fusion for land use classification over Greater Cairo and Giza to overcome the aforementioned limitations. In addition, we also checked if the introduction of a new land use class could better capture the differences between the optical and SAR based techniques (reported in (Delgado et al., 2013)). This new class may represent areas with human induced changes, that could be permanent or transitory, such as open pits, roads eventually covered by sand and ongoing building activities among others. This new class has been called 'Undefined Anthropogenic Disturbances' (UAD) and is mainly located in desert areas.

In this paper, the effect of optical and radar satellite data fusion in medium spatial resolution is tested and applied to analyse the multi-temporal evolution of the urban extension of Greater Cairo for the period from 1998 to 2010.

\section{Study area and remote sensing datasets}

The study area is centred on Greater Cairo and its surroundings, which covers a total area of approximately $50 \times 50 \mathrm{~km}^{2}$ (Fig. 2).

In 1996, Cairo's population was approximately 6.78 million citizens, while in 2006 it reached 7.78 million inhabitants, being reported in 2012 an approximate population of 8.76 (Source: http://statoids.com/ueg.html). Over the 
twentieth century, the Egyptian population increased by nearly 60 million, reaching over 11 million inhabitants in 1907 and more than 72 million in 2006 (Source: CAPMAS). In the last decades the informal construction ${ }^{1}$ (Meikle, 2011) increased dramatically, threatening the Giza's Pyramids World Heritage site. Therefore, we have focused in analysing the built-up increase in the Pyramids Gardens area, named Hadayek Al Ahram, as well as in the entire Greater Cairo for which their results are analysed individually.

We used the freely available archives of Landsat 5 TM and 7 ETM+ optical data, as well as ERS1/2 and Envisat SAR data. The selected SAR datasets comprised the full archive of ERS-1/2 and Envisat ASAR satellites, both in track 436, jointly covering the entire period from 1992 to 2010. The chosen optical satellite imagery was Landsat TM and ETM+ 1998, 2004 and 2010. The specific information is shown in Table 1.

\section{Methodology}

In order to study the land cover dynamics based on the data fusion of SAR and optical data, the implemented methodology follows this three steps (Fig. 3): (i) data preparation; (ii) land use classification; (iii) temporal evolution analysis of the obtained classification maps.

\footnotetext{
${ }^{1}$ The United Nations Centre for Human settlements (UNCHS) defines informal construction as building without getting its corresponding authorization. In addition, in many developing countries building permits were only issued in major towns so building outside of the towns would automatically be informal.
} 


\subsection{Data preparation}

The first step is preparing the various datasets. Initially, SAR imagery is calibrated considering the incidence angle, look angle and the antenna pattern using ESA specifications implemented in NEST (ARRAY, 2013). Then, coregistration, resampling, interferometric coherence computation and geocoding are performed using the DORIS interferometric software from Delft University of Technology (Kampes et al., 2003). Precise orbits from Delft Earth Observation and Space Systems (DEOS) are used to recompute orbital information in order to reduce the coregistration errors. The interferogram image pairs are selected for the subsequent computation of the interferometric coherence based both on short temporal and perpendicular baseline criteria (maximum of 140 days and $120 \mathrm{~m}$ respectively for this study). Coherence can be affected by temporal, spatial and thermal decorrelation factors (Zebker et al., 1992). Hence, a short temporal baseline ensures that there will be minimum changes present in our scene due to the physical changes, and having a short perpendicular baseline minimizes geometric decorrelation (Zebker et al., 1992). This short temporal and perpendicular baseline condition is required to enable the preliminary identification of urban, desert and field areas using the interferometric coherence (Bruzzone et al., 2004). It is worth mentioning the seasonal effects of the sand storms characteristic of our study area around March-April every year. Hence, coherence maps with images acquired during the period with a higher frequency of sand storms in the region (i.e. March-April) were rejected for further analysis. Finally, calibrated SAR images and coherence maps are geocoded using SRTM DEM information (downloaded from the Consortium for Spatial Information (CGIAR-CSI))in 
order to have them geometrically corrected.

Radiance Landsat values are computed using the data provided in the Landsat metadata using the radiometric calibration method suggested by USGS (Chander et al., 2009) and implemented in ENVI ESRI software. Four scenes are selected for 2004 and 2010, because of the scan line corrector failure (SLC-off) that occurred on 31st May 2003 (U.S. Department of the Interior, 2013). These four images were acquired within a maximum period of four months, minimizing the urbanization changes in such a short time period. Hence each group of four images is mosaicked in order to fill the gaps, since given any three Landsat 7 SLC-off images, there is a $90 \%$ probability that $>90 \%$ scene coverage can be achieved (Schneider, 2012).

Finally, all SAR images are georeferenced into the geometry of the Landsat data using 30 ground control points (GCPs) obtained by coregistering SAR with the Multi-spectral data. These GPCs are uniformly distributed all over the study area and represent road intersections on the satellite images. The final images are resampled using a first order polynomial, obtaining a final Root Mean Square Error (RMSE) lower than 1 pixel (30 m.) for all the different cases. Optical images are finally cropped to match the SAR data over the study area. At the end of the data preparation all data are unified to the same image size and georeference system of the Universal Tranverse Mercator (UTM) projection (Zone 36N) and Datum World Geodetic System 84 (WGS84). 


\subsection{Land use classification}

Four generic classes are proposed: (i) built-up area, hereafter named 'urban'; (ii) sandy and rocky desert combined in a 'desert' class; (iii) vegetation, crops, garden, grass and agricultural fields named as 'field' and; (iv) 'water' class mainly formed by Nile River and smaller water bodies present in the scene. In addition, we have also defined a new class named 'undefined anthropogenic disturbances' (UAD) that exploits the data fusion approach in order to identify areas inside the desert where anthropogenic disturbances are detectable, such as construction in early stages, cultural heritage sites, open pits and dirt roads (roads covered with sand). This class does not include finished man-made infrastructures. Hence, this class is expected to be characterized by having low coherence and high temporal variability of the radar signal, with high radiance values characteristic of soil and rocks in optical data (see Fig. 4).

Land use classification has been performed for computing land cover maps with the aforementioned five classes and finally, we have investigated the relationship between the UAD class with built-up areas classified in subsequent LULC maps.

In order to produce land use land cover (LULC) maps with SAR and optical imagery, neural network supervised classifier has been selected due to the higher accuracy reported by Chettri et al. (1992) and Cetin et al. (2004).

We decided to give equal weight to the information derived from each sensor in the mixed sensor approach. Hence, the designed data fusion supervised classifier have equal number of input bands from the different sensors.

The input data selected for the classifier consists in 5 information bands 
of the multi-spectral imagery and 5 information bands derived from the SAR datasets, as follows: (i) near IR; (ii) shortwave IR-1; (iii) thermal IR; (iv) shortwave IR-2; (v) Normalised Difference Vegetation Index (NDVI); (vi) temporal average calibrated SAR in decibel scaled (dB); (vii) temporal standard deviation of calibrated SAR signal per pixel in dB; (viii) normalized temporal standard deviation in $\mathrm{dB}$; (ix) ratio of maximum to minimum calibrated SAR signal per pixel (Bruzzone et al., 2004) and; (x) interferometric coherence (Hanssen, 2001) defined as (Eq. 1);

$$
\left|\hat{\gamma}_{i}\right|=\frac{\left|\sum_{k=1}^{N} y_{M_{k}} \cdot y_{S_{k}}^{*}\right|}{\sqrt{\sum_{k=1}^{N}\left|y_{M_{k}}\right|^{2} \cdot \sum_{k=1}^{N}\left|y_{S_{k}}\right|^{2}}}
$$

where $\left|\hat{\gamma}_{i}\right|$ is the magnitude of the interferometric coherence for pixel $i$, estimated using a window of $\mathrm{N}$ pixels centred at pixel $i$, using the complex values of master $\left(y_{M_{k}}\right)$ and slave $\left(y_{S_{k}}\right)$ images, and $\langle\cdot\rangle^{*}$ being the complex conjugate operator.

Fig. 4 shows qualitatively the expected distribution of the five classes in the interferometric coherence and Shortwave IR-2 (SWIR-2) feature space derived from the SAR and optical sensors. It is noteworthy that the UAD class has low coherence values such as water and field classes, but also high values in SWIR-2 such as desert. Hence, only a combination of sensors would detect this new class.

As mentioned before, the classifier is designed based on artificial neural networks for land use classification. Among the different network typologies, the feed-forward back-propagation multi-layer perceptron (MLP) was selected, being the most commonly used neural network for remote sensing 
(Atkinson \& Tatnall, 1997). It has shown its successful application for land cover classification purposes (Simone et al., 2002; Frate et al., 2007).

Concerning the number of nodes (named neurons) in the hidden layer, we selected for our study the heuristic by Kanellopoulos \& Wilkinson (1997) and Hush (1989), in which the number of neurons in hidden layer is equal to 3 times the number of input bands.

\subsection{Validation approach}

The validation of the classification maps is performed by visual inspection of the very high resolution imagery ( $<3$ meters) copyrighted by DigitalGlobe and available in Google Earth, selecting different point sets for the time periods 2004 and 2010. It is possible to do this due to the historical datasets available. We computed the accuracy of the final classification maps using the overall accuracy (or overall success rate) and also the agreement occurring by chance using the kappa index (Cohen, 1960), as performed by Congalton (1991) and Mather (2004).

\subsection{Temporal evolution analysis}

After obtaining the five-class LULC maps for the different time periods, we identify pixels that remained stable and those that underwent changes from one land use class to another between 1998 and 2010. Non-realistic changes are also detected and labelled as mis-classified pixels, by assuming that: 1) once a pixel is urban, it will stay urban in the following periods; 2) water cannot turn into urban, field or desert; 3) fields can only become urban 
or UAD, but not desert or water. In our study area the water class mainly correspond to the River Nile, and has been stable during the considered time period.

\section{Results}

\subsection{Land use classification}

The resulting supervised land use classifications maps are shown for 1998 and 2010 in Fig. 5. Their analysis can be found in the discussion section.

The kappa index shows very good degree of accuracy (higher than 0.82) for both 2004 and 2010 land cover maps.

The spatial extents and locations of the results showed in Fig. 8 and Fig. 9 are represented in Fig. 7.

\subsection{Temporal evaluation of the classified land use/cover maps}

The land use maps were analysed in order to ensure the feasibility of the existence of different classes based on their evolution. Therefore, a comparative analysis was done taking into account all the classification maps for identification of mis-classified pixels. The 1998, 2004 and 2010 classification maps were analysed together and it was established that changes have to stay coherent for the whole time span analysed. As a result, both the urban expansion and the stable areas in Greater Cairo are computed and mapped (see urban evolution map in Fig. 6).

Stable areas around the Giza Pyramids (Fig. 8, left) show the detected permanent UAD areas, confirming the assumption that UAD class would 
include Cultural Heritage sites with intense transit of visitors. In addition, the Fig. 8 right, shows that the built-up evolution in Hadayek Al Ahram area increased much more during the period from 2005 to 2010 than before.

By applying these criteria three groups were found:(i) stable (non-varying);(ii) varying and;(iii) misclassified pixels. The non-varying pixels are $69 \%$ and the varying ones are $22 \%$. Therefore, the total misclassified pixels are the $8 \%$ of the total number of pixels. Fig. 8 shows that the site of the Giza Pyramids is classified as stable UAD class. Hence, this supports our hypothesis that UAD represents Cultural sites with intense transit of visitors as well.

In 2010 , the total constructed area equals $655 \mathrm{~km}^{2}$ which corresponds to an increase in built-up areas of $72 \%$ since 1998. Of the $274 \mathrm{~km}^{2}$ of newly constructed areas, 37\% are situated in former desert areas. Between 2004 and 2010, half of newly constructed area is situated in the Nile floodplain (49\%), while in the desert is $33 \%$ and $18 \%$ in UAD (see Tab. 3). This matches results obtained by de Noronha Vaz et al. (2011a), where the construction activities in the floodplain appeared to be more important than in the desert for the more recent time period. Additionally, in 2010 around $100 \mathrm{~km}^{2}$ are identified as undefined anthropogenic disturbances (UAD), and part of this extension is identified as urban in 2013 (Fig. 9).

\subsection{Built-up sprawl in Hadayek Al Ahram (Pyramids Gardens)}

The results of the built-up expansion obtained from the temporal evolution analysis are detailed in Table 3.

In 1998, the built-up extent in Hadayek Al Ahram was about $1.01 \mathrm{~km}^{2}$. However, from 1998 to 2010, the built-up extent increased by $5.32 \mathrm{~km}^{2}$, occupying over $532 \%$ more area in 2010 than in 1998. In this case, since the 
Pyramids Gardens area is located completely inside the desert plateau, the new constructions appeared in desert and UAD detected areas in the previous LUCL maps. During the period from 1998 to 2004, one third of the total constructions were built up, while in the period from 2004 to 2010 the growth accelerated, with the identified new constructions of this period more than two times that observed in the previous period (Table 3).

\section{Discussion}

The data fusion approach also enables to identify areas where undefined anthropogenic disturbances are potentially going on, such as early construction stages of new buildings (black pixels in Fig. 5). Moreover, the UAD class also represents arid areas of transit like dirt roads (asphalt roads eventually covered with sand) or areas with high human activity in cultural heritage sites, such as the surroundings of the Giza Pyramids area (Fig. 8).

Fig. 6 shows the temporal evolution of the built-up areas in the Greater Cairo region. In 1998 almost no built-up area was constructed outside the floodplain, but since the government started encouraging people to construct in arid areas, the new built-up area grew both inside and outside the floodplain, the growth in the desert between 1998 and 2004 being more significant. Despite government efforts, construction has not stopped in the floodplain.

The UAD class shows values in the thermal infrared similar to the ones measured for 'urban' and 'desert' classes. In addition, the UAD areas has as low coherence values as the ones found in 'water' and 'field' classes. This means that this new UAD class represents areas that had changed during

the analysed time period. It is remarkable that the new class completely 
overlaps the other classes and, therefore, its detection is only possible with the proposed data fusion approach.

The evolution of the detected areas classified as undefined anthropogenic disturbances is also analysed. $17 \mathrm{~km}^{2}$ of permanent areas of UAD have been detected during the period between 1998 to 2010. These permanent areas can be attributed to intense transit in cultural heritage sites as well as open air mining activities or traffic in dirt roads. Since 2004, $16 \mathrm{~km}^{2}$ of UAD areas appeared, which remained invariant up to 2010. In 2010, around $67 \mathrm{~km}^{2}$ of new UAD areas appeared in desert areas. This increase may have been caused by the early stages of new construction works. Moreover, from 1998 to 2010 , about $71 \mathrm{~km}^{2}$ of new urban areas $(26 \%$ of the total new built-up areas) were constructed in areas which had been classified as UAD in previous land use maps. These results also support our hypothesis that the UAD class represents construction areas in early stages of development because part of the detected UAD areas in one period, evolve into urban areas in the next one. From 1998 to 2010, urbanization in both field and desert areas close to Cairo increased continuously. Between 1998 and 2004, new urban areas were constructed more in the nearby desert than in field areas, but the trend changed during the period from 2004 to 2010. However, in the land use map of 2010, $68 \mathrm{~km}^{2}$ of UAD areas were detected in previously desert areas, part of which may become urban areas in the future (Fig. 9).

\section{Conclusion}

In this study we have applied a data fusion classification approach for quantifying the Greater Cairo urban sprawl from 1998 to 2010 with medium 
resolution optical and SAR data. This is useful in detecting areas affected by anthropogenic activities even if the natural environment does not show a significant change using only medium resolution optical imagery from space. This is only valid for short time lapses and short baselines in the image pairs used in the interferometric coherence computation. The individual limitations of SAR and optical images in detecting UAD areas in the desert have been overcome by mixing both sensors and defining a new class.

Including the new UAD class made it possible to detect construction areas at early stages. Also areas disturbed by other activities than building, such as the intense pressure related to tourist activities at the Giza Pyramid plateau were identified within this class. The identification of UAD is helpful for determining the built-up extension of rapidly changing environments such as Greater Cairo.

The extent of built-up areas in Greater Cairo increased by $73 \%$ between 1998 to 2010, corresponding to an average annual growth rate of $4.7 \%$. However, an increase of $500 \%$ in 13 years is detected at Hadayek Al Ahram (Pyramids Gardens), at close proximity to the Giza Pyramids.

The potential of this data fusion approach requires the availability of suitable optical and SAR data. With the new generation of remote sensing satellites, higher resolution SAR and optical data is available, facilitating a more detailed analysis of the land cover dynamics in both temporal and spatial resolution. 


\section{Acknowledgements}

This research is in the framework of the APLADYN project funded by the STEREO II-program of the Belgian Science Policy-project SR/00/132. This paper could not be possible without the help of Dr. V. De Laet as well as all the people from inside and outside Delft University of Technology whose comments helped to improve the quality of this manuscript, specially P. Mahapatra, L. Iannini and M. Caro Cuenca. The authors acknowledge the use of LandsatTM and ETM+ images available from http://earthexplorer.usgs.gov and the SAR imagery provided by ESA under the CAT-1 C1P.8230. 


\section{References}

ARRAY (2013). NEST-Calibration Operator. URL: http://corp.array . $\mathrm{ca} /$ nest-web/help/operators/CalibrationOp.html.

Atkinson, P. M., \& Tatnall, a. R. L. (1997). Introduction Neural networks in remote sensing. International Journal of Remote Sensing, 18, 699-709.

Bruzzone, L., Marconcini, M., Wegmuller, U., Wiesmann, A., Member, S., \& Wegmüller, U. (2004). An advanced system for the automatic classification of multitemporal SAR images.

Cetin, M., Kavzoglu, T., \& Musaoglu, N. (2004). Classification of multispectral, multi-temporal and multi-sensor images using principal components analysis and artificial neural networks: Beykoz case. In XXth International Society for Photogrammetry and Remote Sensing-Congress (pp. 12-23).

Chander, G., Markham, B. L., \& Helder, D. L. (2009). Summary of current radiometric calibration coefficients for Landsat MSS, TM, ETM+, and EO-1 ALI sensors. Remote Sensing of Environment, 113, 893-903.

Chettri, S. R., Cromp, R. F., \& Birmingham, M. (1992). Design of neural networks for classification of remotely sensed imagery. Telematics and Informatics, 9, 145-156.

Cohen, B. (2006). Urbanization in developing countries: Current trends, future projections, and key challenges for sustainability. Technology in Society, 28, 63-80. 
Cohen, J. (1960). A Coefficient of Agreement for Nominal Scales. Educational and Psychological Measurement, 20, 37-46.

Congalton, R. G. (1991). A Review of Assessing the Accuracy of Classifications of Remotely Sensed Data. Remote Sensing of Environment, 46, 35-46.

de Noronha Vaz, E., Caetano, M., \& Nijkamp, P. (2011a). A multi-level spatial urban pressure analysis of the Giza pyramid plateau in Egypt. Journal of Heritage Tourism, 6, 99-108.

de Noronha Vaz, E., Caetano, M., \& Nijkamp, P. (2011b). A multi-level spatial urban pressure analysis of the Giza Pyramid Plateau in Egypt Research Memorandum 2011-43.

Delgado, J. M., Verstraeten, G., \& Hanssen, R. F. (2013). Monitoring the urban expansion of Cairo from 2004 to 2010 through SAR data using a non-parametric supervised classifier. In Proc. Living Planet Symposium 2013, Edinburgh, UK 913 September 2013 (ESA SP-722, December 2013)

1. ESA Communications ESTEC, Noordwijk, The Netherlands.

Frate, F. D., Pacifici, F., Solimini, D., Informatica, D., \& Produzione, S. (2007). Urban Land Cover in Rome , Italy , monitored by single-parameter multi-temporal SAR images, . (pp. 1-5).

Hanssen, R. F. (2001). Radar Interferometry: Data Interpretation and Error Analysis. Boston, MA (USA).

Harris, R., \& Wahba, M. (2002). The Urban Geography of Low-Income Housing : Cairo ( 194796 ) Exemplifies a Model. International Journal of Urban and Regional Research, 26, 58-79. 
Hassan, A. A. M. (2011). Change in the urban spatial structure of the Greater Cairo metropolitan area, Egypt. Archives, XXXVIII, 133-136.

Hush, D. (1989). Classification with neural networks: a performance analysis. In Proceedings of the IEEE International Conference on Systems Engineering, Dayton, Ohio, USA (pp. 277-280).

Kampes, B. M., Hanssen, R. F., \& Perski, Z. (2003). Radar Interferometry With Public Domain Tools. In Third International Workshop on ERS SAR Interferometry "FRINGE 2003" (p. 6 pp). Frascati, Italy.

Kanellopoulos, I., \& Wilkinson, G. (1997). Strategies and best practice for neural network image classification. International Journal of Remote Sensing, 18, 711-725.

Mather, P. M. (2004). Computer Processing of Remotely-Sensed Images.

Meikle, J. (2011). Note on: Informal Construction. Washington D.C., USA: World Bank. URL: http://siteresources.worldbank.org/ICPINT/ Resources/270056-1255977007108/6483550-1257349667891/01.02_ ICP-TAG04_ConstructionNote.pdf.

Milisavljevic, N., Closson, D., \& Bloch, I. (2010). Detecting human-induced scene changes using coherent change detection in SAR images. In ISPRS TC VII Symposium- 100 Years ISPRS (pp. 389-394). volume XXXVIII.

Schneider, A. (2012). Monitoring land cover change in urban and peri-urban areas using dense time stacks of Landsat satellite data and a data mining approach. Remote Sensing of Environment, 124, 689-704. 
Shetawy, A. A. A., \& El Khateeb, S. M. (2009). The pyramids plateau: A dream searching for survival. Tourism Management, 30, 819-827.

Simone, G., Farina, a., Morabito, F., Serpico, S., \& Bruzzone, L. (2002). Image fusion techniques for remote sensing applications. Information Fusion, 3 , $3-15$.

Stewart, D. J., Yin, Z.-y., Bullard, S. M., \& Maclachlan, J. T. (2004). Assessing the spatial structure of urban and population growth in the greater Cairo area, Egypt: a GIS and imagery analysis approach. Urban Studies, 41, $95-117$.

Sutton, K., \& Fahmi, W. (2001). Cairo's urban growth and strategic master plans in the light of Egypt's 1996 population census results. Science, 18, 135-149.

UNESCO, W. H. C. (2008). Operational Guidelines for the Implementation of the World Heritage Convention. URL: http://www. unesco.org.

U.S. Department of the Interior (2013). SLC-off Products: Background. URL: http://landsat.usgs.gov/products_slcoffbackground.php.

Vermeiren, K., Van Rompaey, A., Loopmans, M., Serwajja, E., \& Mukwaya, P. (2012). Urban growth of Kampala, Uganda: Pattern analysis and scenario development. Landscape and Urban Planning, 106, 199-206.

Zebker, H. A., Member, S., \& Villasenor, J. (1992). Decorrelation in Interferometric Radar Echoes. IEEE Transactions on Geoscience and Remote Sensing, 30, 950-959. 
Figure 1: Location of the study area in Greater Cairo, Egypt. 
Figure 2: Egypt population figures from 1882 to 2006 (Source:CAMPAS). 
Figure 3: Methodology flow diagram for analysing the land use dynamics by fusing SAR and optical imagery. 
Figure 4: Qualitative classes distribution in the interferometric coherence and short-wave infrared (SWIR-2) feature space. 
(a)b)

192810

Lawhd

corever

maxp

Figure 5: Land use classification maps obtained for 1998 (a)) and 2010 (b)). UAD class (in black) detects the areas which had suffered any change during the analysed period. 
Figure 6: Spatial extents for full area of study (cian), Fig. 8 (red) and Fig. 9 (black). 
Figure 7: Built-up evolution of Greater Cairo since 1998 to 2010 computed considering the criteria described in section 3.4. Floodplain is located between the desert edge lines. Desert is located at west and east of the respectives left and right desert edge lines. 
Figure 8: Zoom of stable areas(left) and built-up evolution (right) in Hadayek Al Ahram area (ROI) obtained. 
Figure 9: Mixed sensor land use map of 2010 overlaid with Cairo street features created in June 2013 (C) OpenStreetMap contributors), showing the correspondence between the UAD class detected in 2010 and the new streets and urbanization areas in 2013. 
Table 1: The selected satellite remote sensing imagery.

\begin{tabular}{cccccc}
\hline Acquisition date & Sensor & Path / Track & Spatial resolution $(\mathrm{m})$ & Signal characteristics & N. images \\
\hline 1998-09-11 & Landsat 5 TM & $176 / 39$ & $30 \times 30$ & Visible, NIR, SWIR-1/2, Thermal & 1 \\
$2004-04-12 / 2004-07-17$ & Landsat 7 ETM+ & $176,177 / 39$ & $30 \times 30$ & Visible, NIR, SWIR-1/2, Thermal & 4 \\
$2010-05-15 / 2010-06-07$ & Landsat 7 ETM+ & $176,177 / 39$ & $30 \times 30$ & Visible, NIR, SWIR-1/2, Thermal & 4 \\
1992-06-01 /2001-01-04 & ERS-1/2 SAR & 436 & $4 \times 20$ & Microwave (C band) & 6 \\
2003-11-20 /2010-09-09 & Envisat ASAR IS2 & 436 & $4 \times 20$ & Microwave (C band) & 18 \\
\hline
\end{tabular}


Table 2: Confusion matrix, kappa index and overall accuracy of the resulting land use maps. Google Earth data is used as ground truth.

\begin{tabular}{cccccccc}
\hline \multirow{2}{*}{ Year } & GoogleEarth & \multicolumn{4}{c}{ Land use classification map } & \multirow{2}{*}{ Accuracy criteria } \\
\cline { 2 - 6 } & ground truth & Urban & Desert & Water & Fields & UAD & \\
\hline \multirow{3}{*}{2004} & Urban & $\mathbf{3 6 9}$ & 32 & 0 & 32 & 4 & kappa index (\%) \\
& Desert & 96 & $\mathbf{1 1 2 1}$ & 2 & 29 & 38 & $82.47 \%$ \\
& Water & 1 & 0 & $\mathbf{5 2}$ & 9 & 0 & Overall accuracy \\
& Fields & 42 & 4 & 2 & $\mathbf{7 8 9}$ & 5 & $88.54 \%$ \\
\hline \multirow{4}{*}{2010} & UAD & 1 & 8 & 0 & 0 & $\mathbf{2 5}$ & \\
& Urban & $\mathbf{3 4 2}$ & 37 & 1 & 20 & 0 & kappa index (\%) \\
& Desert & 50 & $\mathbf{8 9 0}$ & 0 & 8 & 15 & $86.24 \%$ \\
& Water & 3 & 0 & $\mathbf{3 0}$ & 5 & 0 & Overall accuracy \\
& Fields & 45 & 4 & 0 & $\mathbf{6 4 3}$ & 2 & $90.93 \%$ \\
& UAD & 0 & 3 & 0 & 0 & $\mathbf{3 1}$ & \\
\hline
\end{tabular}


Table 3: Origin of new built-up areas $\left(\mathrm{km}^{2}\right)$ for Greater Cairo and Hadayek Al Ahram area. Values obtained from the temporal evolution analysis considering only feasible changes.

\begin{tabular}{c|ccc|ccc}
\hline & \multicolumn{3}{|c}{ Greater Cairo } & \multicolumn{3}{c}{ Hadayek Al Ahram } \\
Class & $\mathbf{1 9 9 8 - 2 0 0 4}$ & $\mathbf{2 0 0 4 - 2 0 1 0}$ & subtotal & $\mathbf{1 9 9 8 - 2 0 0 4}$ & $\mathbf{2 0 0 4 - 2 0 1 0}$ & subtotal \\
\hline Desert & 59.0 & 41.8 & $\mathbf{1 0 0 . 8}$ & 1.4 & 2.2 & $\mathbf{3 . 6}$ \\
UAD & 48.7 & 22.8 & $\mathbf{7 1 . 5}$ & 0.5 & 1.2 & $\mathbf{1 . 7}$ \\
Field & 39.8 & 62.1 & $\mathbf{1 0 1 . 9}$ & - & - & - \\
\hline subtotal & 147.5 & 126.7 & $\mathbf{2 7 4 . 2}$ & 1.90 & 3.4 & $\mathbf{5 . 3}$ \\
\hline
\end{tabular}


Population in Egypt (1882-2006)

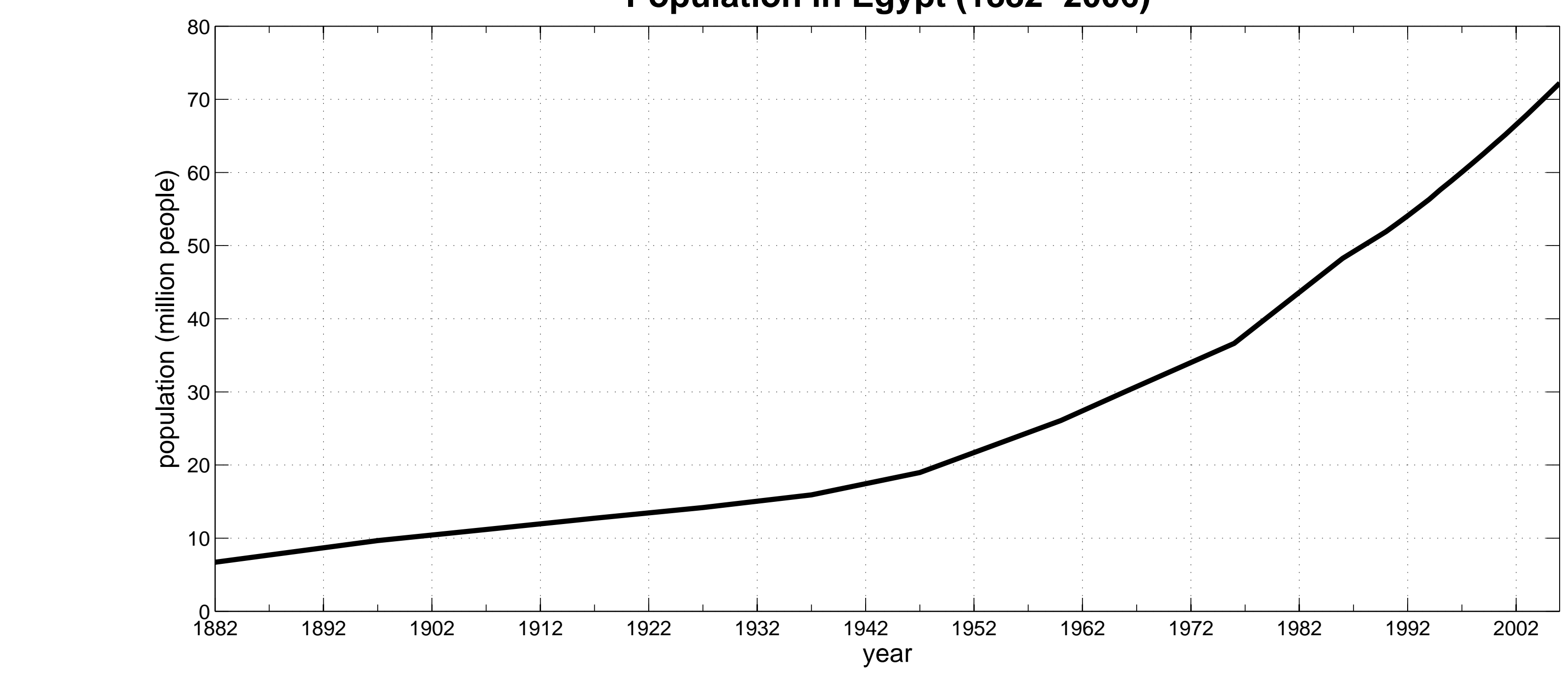




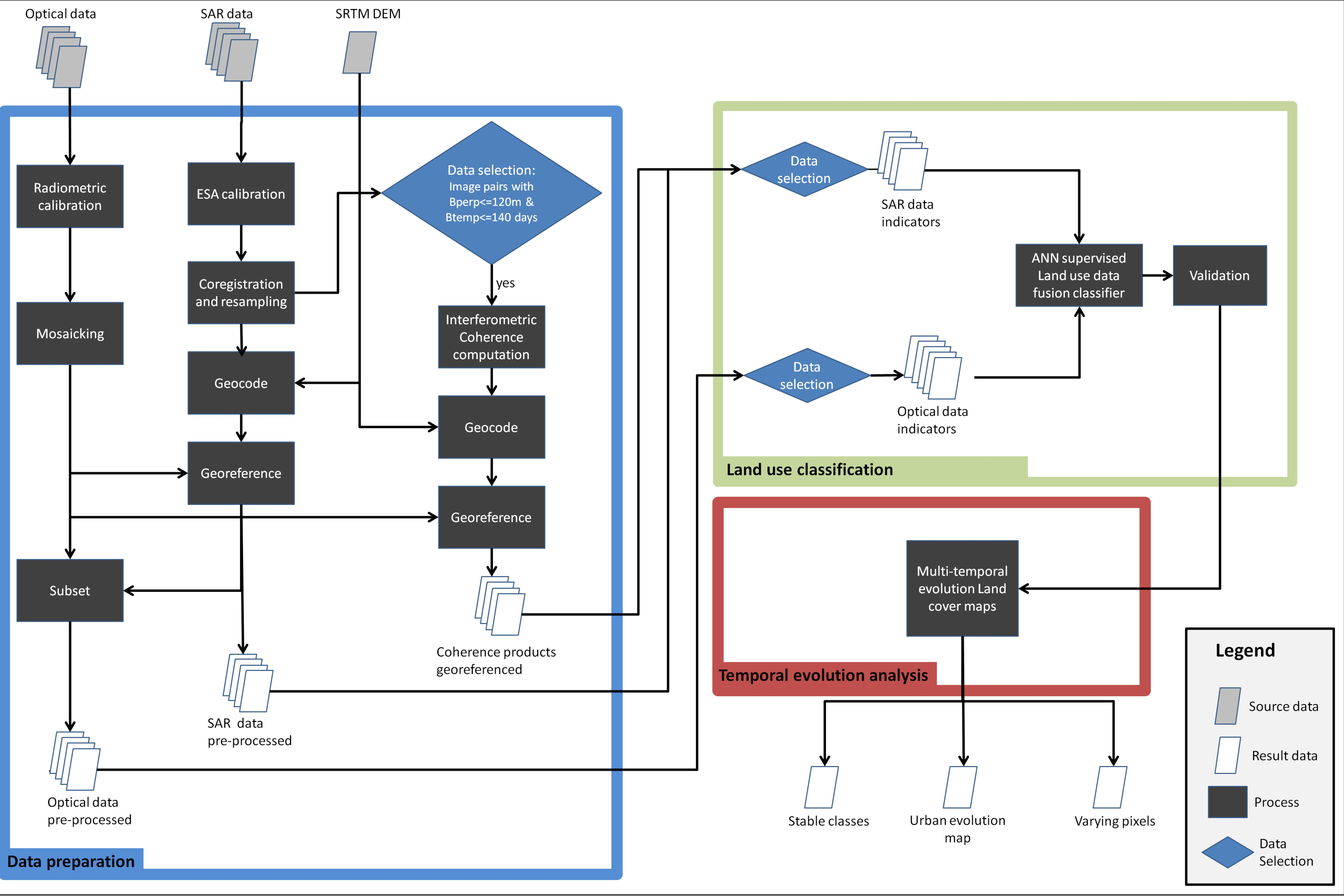




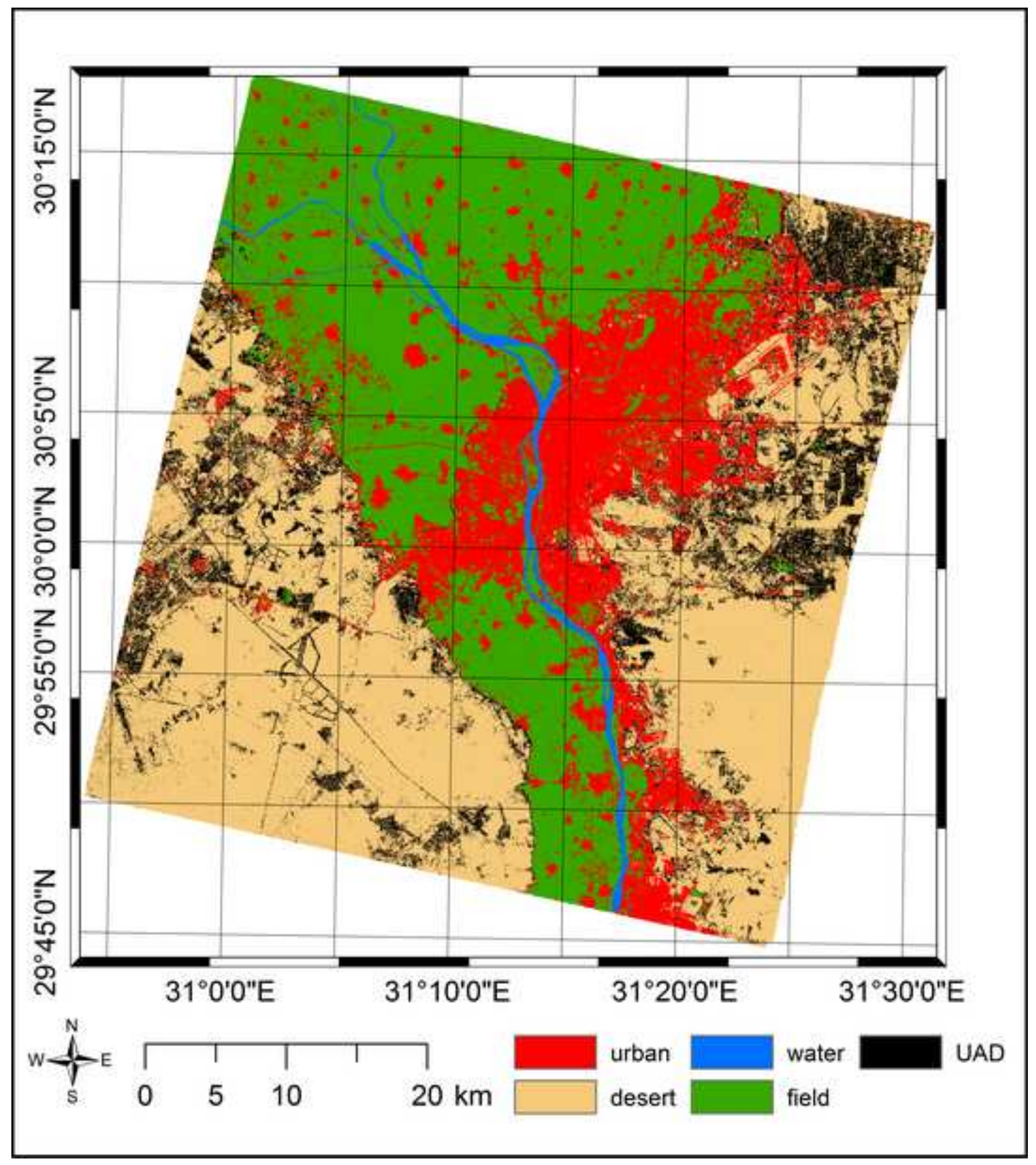




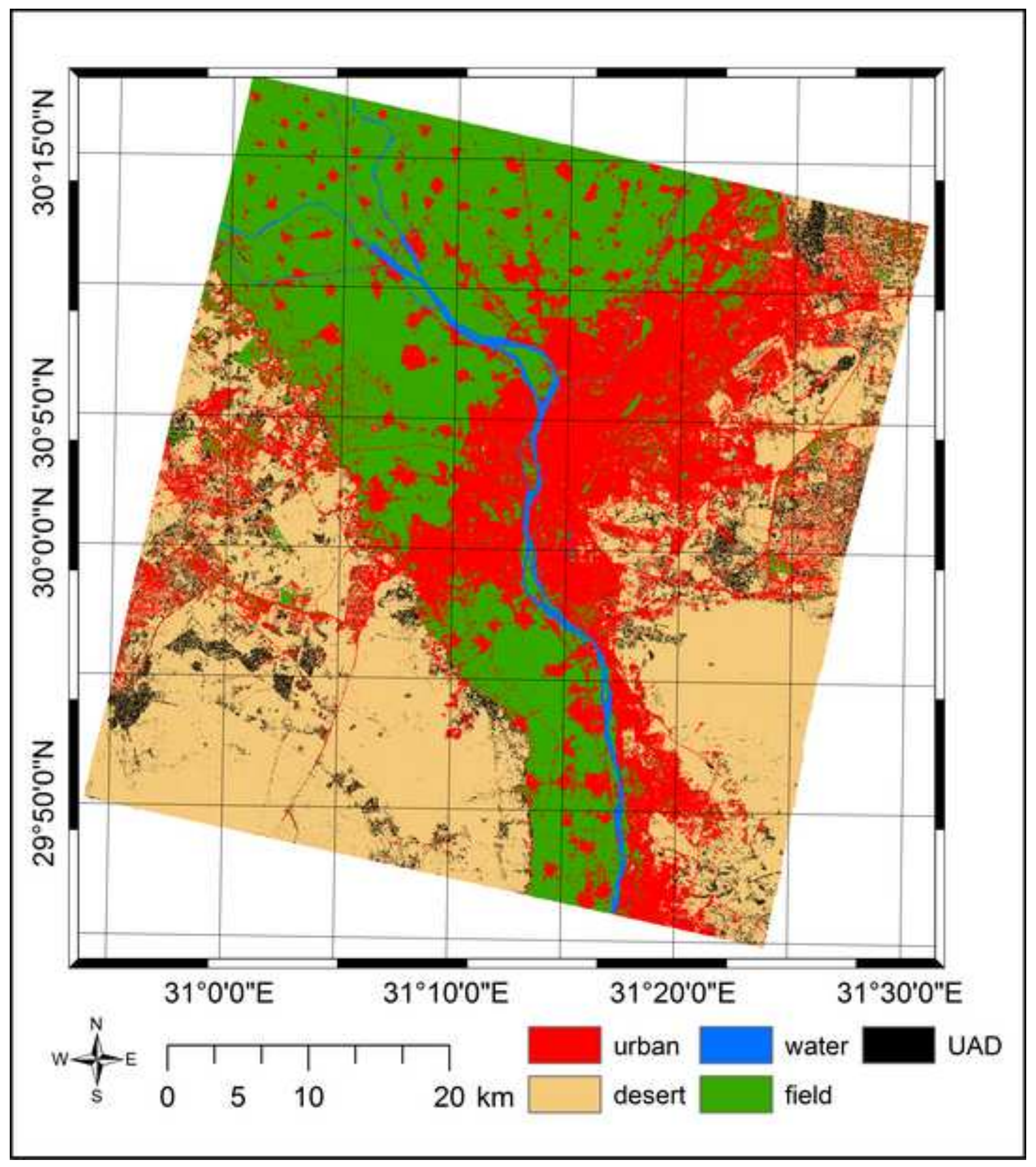




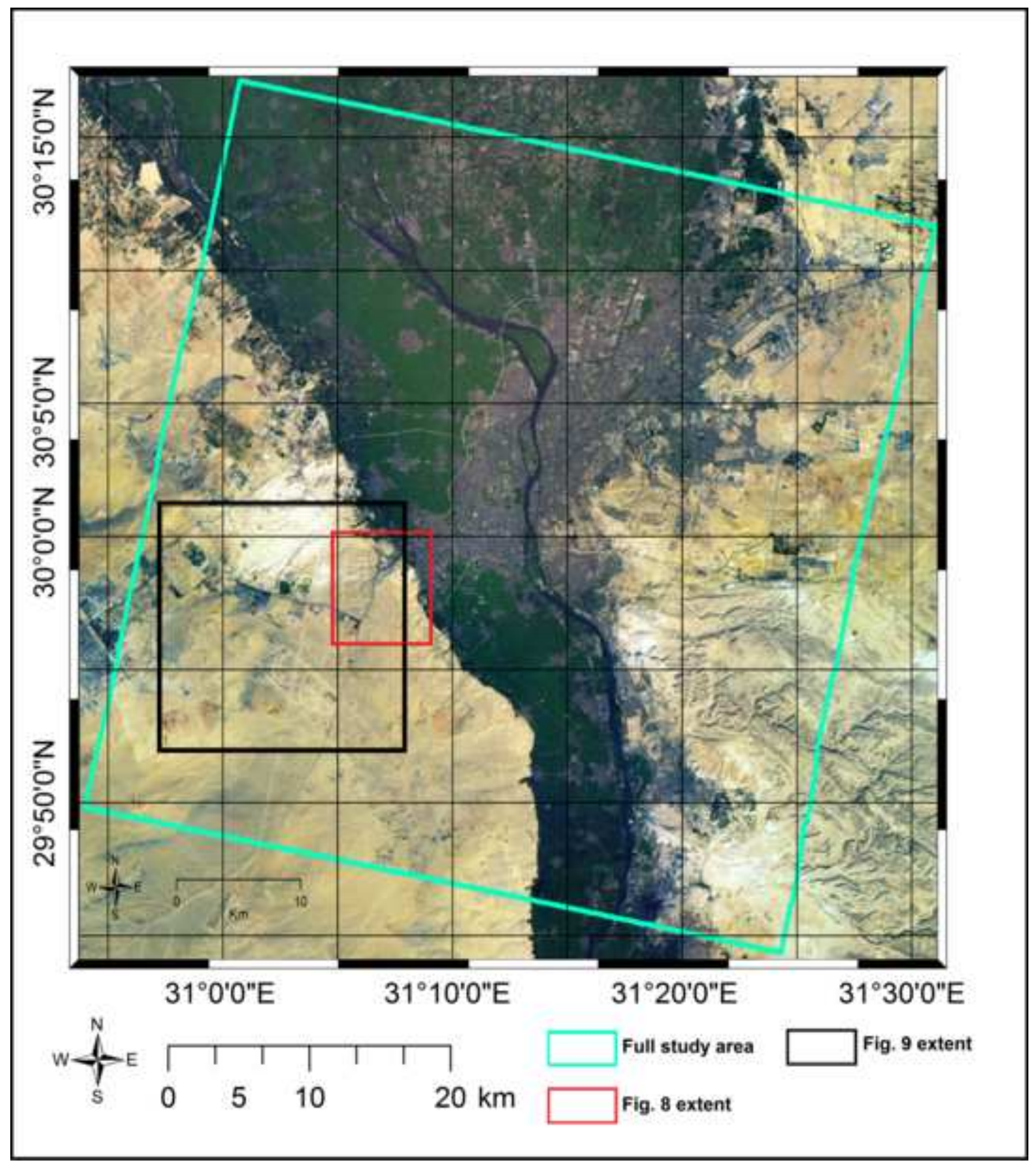




\section{$\pi$}

\section{Figure7}

:

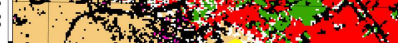

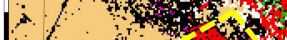

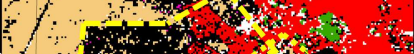

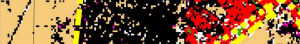

1 .

$\therefore$.

\%-

$x+10$

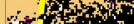

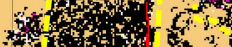

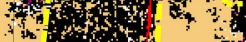

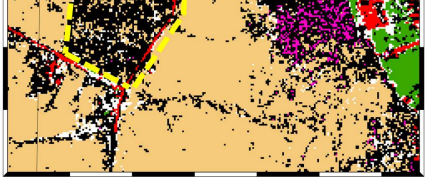

$31^{\circ} 5^{\prime} 0^{\prime \prime E}$

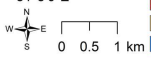

stable urban stable deser stable water torses

(1)

$\left.3 x^{2}+4\right)^{2}$

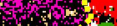

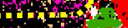
a 8 of 50

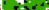
$-340$

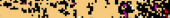

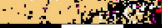
stable field stable UAD ROI varying pixels WHS Giza
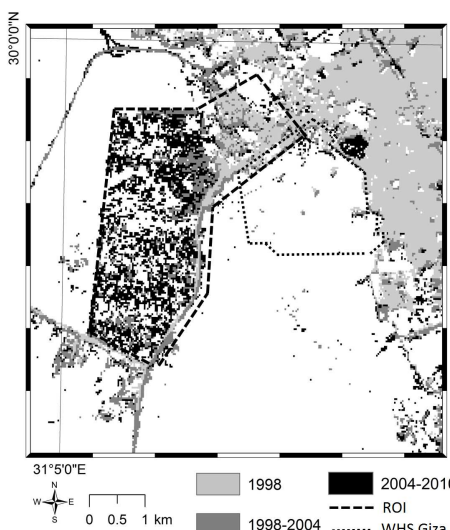

1998

2004-2010

1998-2004
ROI

WHS Giza 






